\title{
MENEROPONG PENDIDIKAN ISLAM DI MUHAMMADIYAH
}

\section{STUDYING ISLAMIC EDUCATION IN MUHAMMADIYAH}

\author{
Eka Damayanti'1), M. Aris Akin ${ }^{2)}$, Nurqadriani ${ }^{3)}$, Suriyati ${ }^{4)}$, Hadisaputra ${ }^{5)}$ \\ 1)Fakultas Tarbiyah dan Keguruan, UIN Alauddin Makassar, Indonesia \\ 2)Program Studi Manajemen Pendidikan Islam, STAI DDI Pangkep, Indonesia \\ 3)Program Studi Pendidikan Agama Islam, STAI Yapis Takalar, Indonesia \\ 4)Fakultas Tarbiyah dan Ilmu Keguruan, Institut Agama Islam Muhammadiyah Sinjai, Indonesia \\ 5)Fakultas Keguruan dan Ilmu Pendidikan, Universitas Muhammadiyah Makassar, Indonesia \\ eka.damayanti@uin-alauddin.ac.id ${ }^{1}$,, arisakin1983@gmail.com ${ }^{2}$, anhyaryani0@gmail.com ${ }^{3}$, \\ suriyati.iaim@gmail.com ${ }^{4}$ ), hadisaputra@unismuh.ac.id(5)
}

\begin{abstract}
Abstrak
Muhammadiyah merupakan organisasi sosial kemasyarakatan yang dikenal sebagai salah satu pelopor pembaharuan pendidikan Islam di Indonesia yang masih bertahan bahkan mengalami perkembangan kuantitatif yang sangat pesat. Penelitian ini bertujuan untuk menguraikan persyarikatan Muhammadiyah dan kegiatannya dalam bidang Pendidikan Islam, dari awal berdirinya pada tahun 1912 yang masih dalam zaman penjajahan hingga era 4.0. Penelitian yang jenis kepustakaan (library research) ini dilakukan dengan cara menelusuri buku, artikel, dan jurnal terkait sesuai dengan fokus penelitian. Analisis data pada penelitian ini menggunakan teknik deskriptif naratif. Hasil temuan menunjukkan bahwa pendidikan Muhammadiyah mengusung spirit pendidikan Islam transformatif yang mendorong peserta didik tidak hanya menguasai ilmu pengetahuan dan teknologi yang diajarkan, tetapi juga menginternalisasikan ilmu yang telah dipelajari ke dalam dirinya, sehingga mengalami proses transformasi diri dan mampu terlibat dalam menyelesaikan masalah yang ada di masyarakat. Metode dakwah Muhammadiyah fokus pada pengorganisasian pembagunan sosial dan pekembangan pendidikan berbasis keislaman yang dinamis dari berbagai aspek yang diwujudkan dalam bentuk sekolah berbasis Islam sehingga gerakan Muhammadiyah tidak hanya mencakup dimensi duniawi saja, namun juga dimensi ukhrawi.
\end{abstract}

Kata Kunci: pendidikan islam, Islam transformatif, persyarikatan muhammadiyah

\begin{abstract}
Muhammadiyah is a social organization known as one of the pioneers of Islamic education reform in Indonesia which still survives and even experiences very rapid quantitative development. This study aims to describe the Muhammadiyah association and its activities in the field of Islamic Education, from its inception in 1912 which was still in the colonial era until the era of 4.0. This type of library research is carried out by browsing related books, articles, and journals according to the research focus. Data analysis in this study used descriptive narrative technique. The findings show that Muhammadiyah education carries the spirit of transformative Islamic education that encourages students not only to master the science and technology that is taught, but also to internalize the knowledge that has been learned into themselves, so that they experience a process of self-transformation and are able to be involved in solving problems that exist in the world. public. The Muhammadiyah da'wah method focuses on organizing social development and the development of dynamic Islamicbased education from various aspects which are manifested in the form of Islamic-based schools so that the Muhammadiyah movement does not only cover the worldly dimension, but also the hereafter dimension.
\end{abstract}


Keywords: islamic education, transformative Islam, muhammadiyah association

How to Cite: Damayanti, E., Akin, M. A., Nurqadriani, Suriyati, \& Hadisaputra. (2021). Meneropong pendidikan Islam di Muhammadiyah. Al asma: Journal of Islamic Education, $3(2), 250-262$.

\section{PENDAHULUAN}

Sebagai organisasi kemasyarakatan, Muhammadiyah pada awalnya didirikan oleh KH Ahmad Dahlan di desa Kauman Yogyakarta pada tanggal 18 November 1912/8 Dzulhijjah 1330 H. KH Ahmad Dahlan atau nama kecilnya adalah Muhammad Darwis adalah pegawai kesultanan kraton Yogyakarta, yang mengemban amanah sebagai seorang khatib dan memiliki profesi sebagai seorang pedagang. Muhammadiyah lahir dari rasa keprihatinan KH Ahmad Dahlan melihat kondisi umat Islam kala itu yang jumud, serta penuh dengan ajaran-ajaran yang berbau mistik. Sesuai dengan tuntunan Al-Qur'an dan As-Sunnah, KH Ahmad Dahlan tergerak untuk mengajak umat Islam kembali kepada ajaran Islam yang benar (Tim Penulis, 2020b).

Ahmad Dahlan memperoleh penolakan ketika pertama kali memulai kegiatan dakwah, namun karena kesabaran dan ketekunannya, ia diterima oleh keluarga dan teman dekatnya. Profesinya sebagai pedagang sangat mendukung dakwahnya. Alhasil, dalam waktu singkat dakwah KH Ahmad Dahlan menyebar keluar desa Kauman, sampai ke luar daerah dan pulau Jawa. Untuk menyelenggarakan kegiatan tersebut, didirikanlah Persyarikatan Muhammadiyah. Kata "Muhammadiyah" secara harfiah berarti "pengikut Nabi Muhammad". Kata "Muhammadiyah" digunakan untuk menghubungkannya dengan ajaran dan jejak perjuangan Nabi Muhammad.

Kelahiran dan keberadaan Muhammadiyah tidak terlepas dari perjuangan $\mathrm{KH}$ Ahmad Dahlan selama melaksanakan ibadah haji di Tanah Suci dan yang kedua kalinya tinggal di sana pada tahun 1903. KH Ahmad Dahlan melalui wadah organisasi Muhammadiyah dengan identitasnya sebagai organisasi pemurni Islam dari segala bentuk tahayul, bid'ah, dan khurafat serta bercorak tajdid (Novriadi \& Syubli, 2021). Selama di Mekkah, KH Ahmad Dahlan menerima ide-ide pembaruan dari ulama Indonesia yang tinggal di sana, seperti KH Fakih dari Maskumambang, KH Nawawi dari Banten, KH Ahmad Khatib dari Minangkabau, dan KH Mas Abdullah dari Surabaya. Tidak hanya itu, Ahmad Dahlan juga terpengaruh setelah membaca buku-buku yang ditulis oleh para tokoh pembaharu Islam, seperti Jamaluddin Al-Afghani, Mumammad Abduh, Muhammad bin Abdil Wahhab, dan Rasyid Ridha. KH Ahmad Dahlan juga mulai melakukan usaha-usaha dengan meluruskan aqidah dan amal ibadah masyarakat Islam di Kauman (Mubaroq, Maulana, \& Basri, 2020). Adanya potensi kecerdasan yang dimiliki oleh Ahmad Dahlan memudahkannya untuk memahami ide-ide pembaruan Islam dan menanamkannya ke dalam dirinya.

Lahirnya Muhammadiyah sebagai gerakan Islam melalui sistem organisasi juga memiliki landasan acuan teologis, sebagaimana yang tercantum dalam Q.S. Ali Imran (3) ayat 104, yang memerintahkan "sekelompok orang untuk untuk mengajak Islam, menyuruh pada ma'ruf serta mencegah dari munkar". Inspirasi dari Q.S. Ali Imran (3) ayat 104 ini menghadirkan Islam dalam semangat Gerakan Muhammadiyah, bukan hanya sebagai doktrin "transendensi" dalam kerangka tauhid, tetapi sebagai doktrin yang mengajak 
untuk melakukan perbuatan baik. Islam murni tidak hanya dipahami secara parsial saja, tetapi dipahami sepenuhnya dan tetap acuh tak acuh terhadap kehidupan. Bersumber pada pemikiran Muhammadiyah, Islam ditampilkan sebagai kekuatan yang bertabiat dinamis dengan tujuan membuat reformasi dalam dunia nyata yang diselenggarakan dalam 2 gerakan, ialah (1) humanisasi (mengajak pada kebaikan) dan (2) emanisipasi ataupun liberasi (pembebasan dari seluruh kemungkaran). Hingga saat itu, Islam diaktualisasikan selaku agama langit yang senantiasa membumi, diisyarati dengan terbitnya fajar baru reformisme ataupun modernisme Islam di Indonesia.

Adapun beberapa sebab sebagai dasar berdirinya Persyarikatan Muhammadiyah, yakni: (1) membersihkan Islam di Indonesia dari pengaruh-pengaruh dan kebiasaan yang bukan Islam, (2) reformulasi doktrin Islam dengan haluan alam bayangan modern, (3) reformulasi ajaran serta pendidikan Islam, serta (4) memperjuangkan Islam dari pengaruh-pengaruh luar (Tim Penulis, 2020c). Sehingga, sejak berdirinya Persyarikatan Muhammadiyah memang telah mengemban misi pencerahan serta pencerdasan dalam bingkai reformulasi pendidikan Islam. Selain itu, Zaini Dahlan (2020) mengungkapkan bahwa Muhammadiyah juga mengusung tugas penghapusan takhayul, bid'ah, khurafat, dan meluruskan keyakinan yang berdasarkan al-Qur'an dan sunnah. Muhammadiyah memiliki metode dakwah yang lebih berfokus pada pengorganisasian pembagunan sosial dan pekembangan pendidikan berbasis keislaman yang dinamis dari berbagai aspek (Luthfi \& Latif, 2020) yang diwujudkan dalam bentuk sekolah berbasis Islam (Kholili \& Fajaruddin, 2020).

Pembaruan pendidikan yang diusung oleh KH Ahmad Dahlan bermula dari ditemuinya konsep ataupun cita-cita baru yang berbentuk perluasan konsep atau cita-cita Islam tradisional yang awalnya berlandaskan pada upaya melahirkan para kyai kemudian diperluas menjadi kyai yang berintelektual atau ulama. Sebagai akibat dari perluasan konsep ini maka timbullah sistem pendidikan model baru yang terintegralistik. Singkatnya, sistem pendidikan tersebut berupaya untuk mengintegrasikan pola pesantren tradisional dengan model sekolah Barat yang dibawa oleh para Kolonial Belanda (Ali, 2010). Menurut Ahmad Ruslan (2020) Muhammadiyah memiliki andil besar sebagai peletak dasar integrasi antara pendidikan pesantren yang bercorak keagamaan dengan pendidikan umum yang didominasi oleh para Kolonial Belanda pada masanya. Faruq (2020) menerangkan bahwa keberadaan Muhammadiyah pada masa Kolonial Belanda sebagai jawaban atau solusi terhadap problematika yang dihadapi masyarakat pribumi, khususnya di bidang pendidikan.

Konsep pendidikan yang integratif ialah konsep pendidikan yang digagas oleh $\mathrm{KH}$ Ahmad Dahlan (Arifin, 2017). Pada dasarnya KH Ahmad Dahlan memadukan konsep pendidikan universal dengan konsep pendidikan agama. Kondisi politik, budaya, dan keadaaan lingkungan kala itu menjadi salah satu faktor timbulnya gagasan mengenai konsep pendidikan Islam integratif. Saat itu KH Ahmad Dahlan mengetahui bahwa pendidikan yang diselenggarakan oleh Kolonial Belanda tidak mencantumkan mata pelajaran agama, seperti mata pelajaran agama Islam. Namun hal berbeda terjadi pada pesantren, surau, dan masjid yang lebih berfokus pada pendidikan agama.

Pemikiran pendidikan yang diperkenalkan oleh KH Ahmad Dahlan dalam Widodo (2019) tersebut dikenal sebagai pendidikan transformatif, karena pendidikan Muhammadiyah memiliki tujuan yang tidak hanya sekedar memberikan bekal yang dapat 
diterapkan dalam berbagai macam situasi kehidupan namun sanggup mentransformasikan diri sendiri dan juga masyarakat. Maka dari itu, pendidikan Muhammadiyah tidak hanya mengajak para peserta didik untuk menguasai IPTEK (Ilmu Pengetahuan dan Teknologi), namun pada saat bersamaan juga mampu melakukan internalisasi dari ilmu yang dipelajarinya ke dalam diri sendiri sehingga terjadi proses transformasi diri, dan juga bersedia membagikan ilmunya kepada masyarakat.

Adapun tujuan dari konsep pendidikan yang diusung oleh KH Ahmad Dahlan tidak hanya membentuk manusia-manusia yang terampil dan menyiapkan masa depan mereka dalam kehidupan dunia sebagaimana tujuan pendidikan Kolonial Belanda. Selain itu, juga bertujuan untuk dakwah amar makruf nahi mungkar. Maka dari itu, dapat dikatakan bahwa tujuan pendidikan Muhammadiyah tidak hanya mencakup dimensi duniawi saja, namun juga dimensi ukhrawi. Oleh KH Ahmad Dahlan, model pendidikan Muhammadiyah disebutnya sebagai model pendidikan yang berkesinambungan yaitu antara perkembangan mental dengan jasmani, antara perasaan dengan akal pikiran, antara keyakinan dengan intelektual, serta antara dunia dengan akhirat (Printina, 2019). Menurut KH Ahmad Dahlan dalam Sukandar dan Hori (2020) pendidikan dalam sekolah Islam bukan hanya bertujuan untuk membekali peserta didik dengan pembelajaran agama saja, tetapi juga dengan pengetahuan umum lainnya.

Maka dari itu, berdasarkan pemaparan sebelumnya penulis melakukan penulisan artikel ini dengan tujuan untuk menguraikan Persyarikatan Muhammadiyah beserta kegiatannya dalam bidang pendidikan Islam yang dijabarkan sebagai berikut: (1) Perkembangan pendidikan Islam dalam ormas (organisasi masyarakat) Muhammadiyah,

(2) Konsep pendidikan yang mencerahkan sebagai dasar nilai Indonesia berkemajuan, dan

(3) Eksistensi pendidikan Muhammadiyah di era 4.0.

\section{METODE PENELITIAN}

Artikel ini disusun berdasarkan penelitian jenis penelitian kualitataif berupa penelitian kepustakaan (library research). Data pada penelitian ini didapatkan berdasarkan dari kegiatan penelusuran buku, artikel, dan jurnal yang relevan dengan fokus penelitian ini yakni tentang persyarikatan Muhammadiyah dan kegiatannya dalam pendidikan Islam. Data dari berbagai literatur yang didapatkan selanjutnya dianalisis menggunakan teknik narasi deskriptif.

\section{HASIL DAN PEMBAHASAN}

\section{Ruh Pembaharuan Pendidikan Islam dalam Muhammadiyah}

Di Indonesia sejak pra kemerdekaan, perkembangan Islam semakin meningkat khususnya di daerah-daerah. Perkembangan tersebut sejalan dengan perkembangan paham Islam dan Ormas Islam yang baru. Masing-masing daerah/kota di Indonesia umumnya telah memiliki paham dan tradisi Islam serta ormas Islam, salah satunya yaitu keberadaan ormas Muhammadiyah (Syafruddin dkk, 2018). Salah satu aktivitas dari ormas Islam berupa menyelenggarakan pendidikan Islam. Melalui pendidikan Islam diharapkan mampu menumbuhkan kesadaran manusia agar menjadi berakhlak mulia dan beribadah hanya kepada Allah SWT (Saihu, 2020). Pembaruan pendidikan Islam tidak dapat dipisahkan dari perkembangan pemikiran Islam itu sendiri, dimana memberikan 
andil besar dan membawa ruh segar dalam melalukan pembaruan pendidikan Islam (Ridlo, 2020).

KH Ahmad Dahlan dikala itu melihat fakta bahwa materi keislaman yang diajarkan ke masyarakat lambat dipahami sehingga menjadi penyebab pendidikan Islam berada pada posisi stagnan dan tradisional. Oleh karena itu KH Ahmad Dahlan melakukan perombakan khususnya dalam hal metode pengajaran dalam bentuk kelas sebagaimana model pembelajaran yang diterapkan dalam sekolah gubernemen. Menurut KH Ahmad Dahlan, materi pendidikan Islam harusnya dikaji melalui pendekatan dan perspektif modern yang sesuai dengan tuntutan zaman, bukan secara tradisional. Masyarakat diajarkan kitab suci al-Qur'an dengan terjemahan dan tafsirnya dengan tujuan supaya masyarakat tidak hanya pandai membaca ataupun melagukan al-Qur'an semata, melainkan dapat memahami makna yang ada di dalamnya (Widiyastuti, n.d.). Metode mengajarkan al Qur'an seperti itu bukan hanya di kulitnya tapi memahami dan mendalami isinya dianggap membuat masyarakat lebih mudah mengamalkan atau menerapkan pesan yang disampaikan dalam al-Qur'an. Hal tersebut menghindari Islam dipahami sebagai dogmatis saja.

KH Ahmad Dahlan mengembangkan metode pembelajaran bercorak kontekstual yang didalamnya memiliki proses penyadaran. Salah satu contoh yang paling sering didengar dalam sejarah bahwa ketika beliau menjelaskan QS al-Ma'un kepada santrisantrinya. KH Ahmad Dahlan menyampaikannya secara berulang-ulang sampai santri itu menyadari bahwa surat itu menganjurkan agar memperhatikan dan menolong fakirmiskin, dan harus mengamalkan isinya. Hal itu terlihat dalam kalimat KH Ahmad Dahlan ketika mengajar:

"Kalian sudah hafal surat al Maun, tapi bukan itu yang saya maksud, Amalkan! Diamalkan, artinya dipraktekkan, dikerjakan! Rupanya Saudara-Saudara belum mengamalkannya. Oleh karena itu, mulai hari ini, Saudara-saudara agar pergi berkeliling mencari orang miskin. Kalau sudah dapat, bawalah pulang ke rumahmu masing-masing. Berilah mereka mandi dengan sabun yang baik, berilah pakaian yang bersih, berilah makan dan minum, serta tempat tidur di rumahmu. Sekarang juga pengajian saya tutup, dan Saudara-Saudara melakukan petunjuk saya tadi."(Salam, 2009).

Disamping itu, teknik interaksi dalam pembelajaran juga dirubah oleh $\mathrm{KH}$ Ahmad Dahlan dengan menggabungkan murid laki- laki dan perempuan secara bersaman yang dimana masyarakat pada saat itu masih menganggap asing model tersebut dan bahkan tidak jarang mereka menyebutnya sebagai model kafir.

Salah satu ciri gerakan yang bernuansa Islam baru dapat disebut "modern" manakala gerakan keagamaan tersebut menggunakan metode "organisasi"(Ali, 1971). Diawal berdirinya, Muhammadiyah telah menggunakan metode "organisasi" dalam menjalankan usahanya pada bidang pendidikan dan amal sosial yang menekankan terhadap pemurnian agama Islam dengan menghilangkan "beban" kultural praktik keagamaan ditengah masyarakat. Sehingga dengan sendirinya Muhammadiyah telah menjadi sebuah gerakan keagaamaan Islam yang modern.

Dalam Muhammadiyah, borjuasi muslim muncul ke permukaan kehidupan sosial, suatu kelas yang dianggap bakal menjadi elemen penting untuk pembentukan Indonesia 
baru (Mas, 2005). Menurut KH Ahmad Dahlan, Muhammadiyah dalam mengelola lembaga pendidikan disamping menerima sistem gubernemen juga tetap memperhatikan nilainilai keislaman yang berlaku sebagaimana sistem pendidikan pada madrasah Diniyah dan Sumatera Thawalib serta tidak terlalu Hollandisator sebagaimana Abdullah Ahmad. Gambaran inilah yang kemudian disebut oleh KH Ahmad Dahlan sebagai upaya mengambil jalan di tengah- tengah.

Corak pendidikan tempo dulu penekanannya adalah pembentukan ataupun pewarisan nilai-nilai keagamaan dan tradisi dalam masyarakat. Sehingga misi pendidikan telah tercapai manakala peserta didik sudah memiliki sikap positif dalam beragama serta dapat memelihara tradisi dalam masyarakat. Namun berbeda dengan prespektif masyarakat dewasa ini yang sudah semakin terdidik dan terbuka yang umumnya lebih rasional, pragmatis dan cenderung berpikir jangka panjang tentunya melihat bahwa pengembangan pendidikan Islam tidaklah sederhana. Sebab memerlukan perencanaan secara terpadu dan menyeluruh. Sebab, perencanaan berfungsi untuk memfokuskan pada sasaran, alokasi dan kontinuitasnya. Perencanaan dapat juga sebagai suatu proses untuk menentukan apa yang akan dicapai, bagaimana mencapainya, siapa yang mengerjakan, dan kapan dilaksanakan, sehingga perencanaan juga memerlukan adanya kejelasan terhadap masa depan yang akan dicapai atau dijanjikan (Fadjar dkk, 2005).

Gagasan pembaharuan yang dicetuskan oleh KH Ahmad Dahlan adalah seruan untuk berijtihad dan menolak taklid serta kembali kepada al-Qur'an dan sunnah. Sehingga bercermin pada ide serta gagasan tersebut, maka pendidikan Islam di Muhammadiyah menekankan terhadap penyiapan lingkungan yang memungkinkan seseorang tumbuh sebagai manusia yang menyadari kehadiran Allah SWT serta menguasai ilmu pengetahuan, teknologi dan seni (Darsitun, 2020).

Dalam usaha pembaharuan Islam dalam bidang pendidikan, Muhammadiyah melakukan modernisasi dengan menyempurnakan kurikulum pendidikan Islam yaitu memasukkan pendidikan agama Islam ke dalam sekolah umum dan sebaliknya pengetahuan sekuler dimasukkan ke sekolah agama.Lebih dari itu Muhammadiyah tidak hanya menawarkan konsep sekolah umum plus, tetapi juga melakukan modernisasi dengan cara mengintegrasikannya dengan sistem asrama (pesantren). Modernisasi dalam konteks lembaga-lembaga pendidikan di Muhammadiyah berlangsung intensif dalam bentuk introduksi elemen kelembagaan pendidikan modern dan subjek-subjek ilmu pengetahuan modern (Yusra, 2018).

KH Ahmad Dahlan dalam melakukan pembaruan dalam bidang pendidikan dalam Syaifuddin, dkk (2019) telah menghasilkan lembaga pendidikan yang memiliki keutuhan dalam sistem dan praktik pendidikannya. Tidak cukup dengan cerdas secara intelektual akan tetapi diimbangi juga dengan kecerdasan spiritual sebagai pondasi diri menjalankan kehidupan dunia dan akhirat. Dalam Muhammadiyah pendidikan juga membekali peserta didik dengan kemampuan soft skill sebagai bekal menjalani hidup. Sehingga, tidak heran pendidikan Muhammadiyah menjadi lembaga pendidikan Islam modern dan menjadi pelopor bagi lembaga yang lain.

Muhammadiyah mengalami perkembangan yang sangat signifikan dalam bidang pendidikan, terutama dari segi kualitas dan kuantitas jumlah lembaga pendidikan yang dimilikinya di seluruh Indonesia. Dalam bidang pendidikan organisasi Muhammadiyah memiliki banyak lembaga pendidikan dari tingkat dasar hingga Perguruan Tinggi 
(Lenggono, 2018). Hingga tahun 2020 ini, berdasarkan data Pimpinan Pusat Muhammadiyah, sumbangan Muhammadiyah telah memiliki amal usaha tingkat TK/TPQ Muhammadiyah sebanyak 4.623, SD/MI Muhammadiyah sebanyak 2.604, SMP/MTs Muhammadiyah sebanyak 1.772, SMA/SMK/MA Muhammadiyah sebanyak 1.143, dan Perguruan Tinggi Muhammadiyah sebanyak 172 (Tim Penulis, 2020a).

\section{Konsep Pendidikan yang Mencerahkan sebagai Basis Nilai Indonesia Berkemajuan}

Konsep pendidikan Islam di Muhammadiyah memiliki basis nilai Indonesia berkemajuan. Konsep Islam Berkemajuaan berjalan beriringan dengan konsep Negara Indonesia, yang mencitakan "memajukan kesejahteraan umum dan mencerdaskan kehidupan bangsa". Islam Berkemajuan dalam pandangan Muhammadiyah, menurut keterangan Haedar Nashir, adalah Islam yang mengandung nilai-nilai kemajuan untuk membangun peradaban yang utama dan menjadi rahmat bagi semesta. Kemajuan dalam pandangan Islam adalah kebaikan yang serba utama karena melahirkan keunggulan hidup lahiriah maupun ruhaniah. Dalam Islam kemajuan dipandang bersifat multiaspek, baik dalam kehidupan keagamaan maupun dalam seluruh dimensi kehidupan, yang melahirkan peradaban utama sebagai bentuk peradaban alternatif yang unggul secara lahiriah dan ruhaniah. Islam berkemajuan ingin mewujudkan kehidupan umat manusia yang tercerahkan melalui transformasi sosial yang bersifat emansipatoris, humanis, liberal, dan transenden (Syam \& Nawawi, 2019).

Dalam buku "Indonesia Berkemajuan Rekonstruksi Kehidupan Kebangsaan Yang Bermakna" yang diterbitkan Pimpinan Pusat Muhammadiyah menjelang Muktamar tahun 2015 di Makassar, dipaparkan bahwa Indonesia Berkemajuan memerlukan basis nilai dan lingkungan strategis yang mendukung terwujudnya proses kehidupan kebangsaan yang maju, adil, makmur, bermartabat, dan berdaulat sebagaimana dicita-citakan para pendiri bangsa. Basis nilai dan lingkungan strategis ini mengacu pada agama sebagai sumber nilai kemajuan, kepemimpinan profetik, institusi yang progresif, pendidikan yang mencerahkan dan keadaban publik. Kelima aspek ini perlu disosialisasikan sehingga menjadi landasan yang kokoh untuk mewujudkan Indonesia Berkemajuan (Tim Penulis, 2015a).

\section{Agama Sumber Nilai Kemajuan}

"Agama sebagai sumber nilai utama yang fundamental berfungsi sebagai kekuatan transendental yang luhur dan mulia bagi kehidupan bangsa. Nilai-nilai agama tercermin dalam Pancasila sebagai Ideologi Negara. Karenanya, agama bagi kehidupan bangsa Indonesia dapat dijadikan sebagai sumber nilai kemajuan. Dalam hal ini, diperlukan kontekstualisasi pemahaman keagamaan di kalangan umat beragama dan bangsa Indonesia agar prinsip-prinsip agama yang positif, inklusif, dan progresif menjadi ruh kemajuan hidup sekaligus menjadi kekuatan pemersatu. Nilai-nilai agama bukan sumber pesan anti kemajuan dan pemecah belah kehidupan kebangsaan. Karenanya Islam dapat menjadi sumber nilai yang penting dan utama bagi usaha-usaha membangun kehidupan kebangsaan menuju Indonesia Berkemajuan."

\section{Pendidikan yang Mencerahkan}

"Indonesia Berkemajuan meniscayakan dukungan sumberdaya manusia yang cerdas dan berkarakter utama. Manusia Indonesia yang cerdas memiliki fondasi iman dan taqwa yang kokoh, kekuatan intelektual yang berkualitas, kepribadian yang utama, dan menjadi pelaku kehidupan kebangsaan yang positif sesuai dengan nilai-nilai yang terkandung dalam Pancasila. Sumberdaya manusia Indonesia yang cerdas dan berkarakter 
utama hanya dapat dihasilkan oleh sistem pendidikan yang "mencerdaskan kehidupan bangsa" sebagaimana diamanatkan Pembukaan UUD 1945. Pendidikan nasional selain mampu menghasilkan manusia Indonesia yang cerdas juga dapat membentuk watak perilaku utama."

\section{Kepemimpinan Profetik}

"Indonesia Berkemajuan sangat ditentukan oleh karakter kepemimpinan dalam seluruh struktur kehidupan kebangsaan. Negara dan bangsa berkemajuan memerlukan karakter kepemimpinan yang progresif, reformatif, inspiratif dan berakhlak mulia yang mampu menyerap aspirasi masyarakat dan mengkristalisasikan nilai-nilai etika keagamaan sebagai landasan kebijakan di pelbagai sector kehidupan kebangsaan. Dalam konteks kehidupan kebangsaan, kepemimpinan profetik adalah kepemimpinan yang memiliki komitmen terhadap kebenaran, mendorong terwujudnya keadilan sosial dan ekonomi, berpihak kepada hak-hak masyarakat, serta mengutamakan kepentingan bangsa dan negara di atas segalanya. Kepemimpinan profetik memiliki kualitas ruhaniah yang memadukan keseimbangan hubungan dengan Tuhan dan dengan sesama umat manusia serta lingkungannya untuk membangun peradaban hidup yang utama."

\section{Institusi yang Progresif}

"Upaya untuk mewujudkan Indonesia Berkemajuan mensyaratkan adanya institusi atau pranata politik yang dapat berfungsi sebagai pendorong (driver) dari kemajuan itu sendiri. Dalam hal ini, sistem demokrasi yang telah menjadi pilihan bangsa Indonesia harus mampu memastikan berjalannya lembaga hukum dan peradilan dengan baik dan independen, berfungsinya pemerintahan dan birokrasi secara efektif dan efisien, dan terbukanya ruang bagi partisipasi publik dalam proses kebijakan dan pengawasan."

"Oleh karena itu, melembaganya peran partisipasi publik dalam proses kebijakan dan pengawasan juga merupakan prasyarat penting bagi terwujudnya Indonesia Berkemajuan. Lembaga-lembaga politik, baik lembaga hukum maupun birokrasi pemerintahan, harus menjamin terbukanya ruang tanpa diskriminasi yang memungkinkan masyarakat luas- organisasi sosial-kemasyarakatan, media, cendekia, organisasi profesi, gerakan sosial dan lembaga swadaya masyarakat dan lembaga-lembaga keagamaan untuk ikut serta dalam membangun Indonesia Berkemajuan."

\section{Keadaban Publik}

"Masyarakat berkemajuan adalah masyarakat yang menjunjung tinggi nilai-nilai keadaban yang luhur. Nilai-nilai keadaban publik yang utama itu bersumber dari ajaran agama dan kebudayaan masyarakat Indonesia yang tumbuh-kembang dalam kehidupan sehari-hari. Agama memiliki peran penting dalam membentuk watak dan perilaku setiap warga Negara dalam hidup berbangsa, bernegara dan bermasyarakat. Keadaban publik yang dibangun di atas prinsip nilai dan etika yang utama merupakan lingkungan strategis yang penting untuk dibudayakan menuju terwujudnya Indonesia Berkemajuan."

Muhammadiyah mengajak kepada seluruh elite bangsa agar tetap konsisten antara kata dan tindakannya, menjunjung tinggi moral yang utama, menunaikan amanat rakyat dan memperjuangkan kepentingan rakyat diatas kepentingan pribadi, kelompok maupun golongan. Muhammadiyah menyadari bahwa Indonesia sebagai negara Pancasila kedepannya akan diperhadapkan dengan berbagai tantangan untuk membawanya menuju Indonesia yang berkemajuan. 'Muhammadiyah mengajak pemerintah di seluruh tingkatan untuk berkomitmen kuat dalam memajukan bangsa dan Negara disertai sikap 
mengedepankan keadilan dan kejujuran, berdiri di atas semua golongan, tidak partisan dan menyalahgunaan kekuasaan, serta mampu menunjukkan jiwa kewarganegaraan. Bersamaan dengan itu dalam kehidupan kebangsaan Muhammadiyah memandang bahwa Indonesia ke depan meniscayakan rekonstruksi sosial-politik, ekonomi, dan budaya yang bermakna yang mensyaratkan kehadiran agama sebagai sumber nilai kemajuan, pendidikan yang mencerahkan, kepemimpinan profetik, institusi yang progresif, dan keadaban publik yang dijiwai nilai-nilai Pancasila yang unggul (Tim Penulis, 2015c).

\section{Eksistensi Pendidikan Muhammadiyah di Era 4.0}

Menurut Ismail dan Risfaisal (2017) Hadirnya Muhammadiyah sebagai lembaga pendidikan Islam di Indonesia merupakan simbiosis mutualistis antara masyarakat muslim dan Muhammadiyah itu sendiri. Maka diusia satu Abad Muhammadiyah dalam dunia pendidikan tentunya dibutuhkan pemikiran keagamaan yang segar, responsif dan solutif bagi umat yang tetap berpegang pada al-Qur'an dan sunnah.

Pendidikan di Persyarikatan Muhammadiyah termasuk kategori kuat dan kokoh. Hal ini dibuktikan dengan eksistensi yang dimilikinya sampai saat ini. Dalam hal kebijakan pemerintah, Muhammadiyah tidak serta merta langsung mengikuti setiap kebijakan perubahan terkait dengan pendidikan. Muhammadiyah selalu mengedepankan sikap kritis dalam menanggapi setiap kebijakan dan perubahan yang ada. Setiap kebijakan sebelumnya dikaji secara mendalam dengan melihat berbagai sudut pandang yang ada, mempertimbangkan relevansi dari implementasi setiap kebijakan tersebut, serta faktor terkait lainnya untuk memperoleh hasil terbaik. Keberadaan pendidikan Muhammadiyah yang mampu melewati berbagai lintasan zaman membuktikan bahwa pendidikan Muhammadiyah layak untuk dijadikan pedoman (Faruq, 2020).

Muhammadiyah terus mengupayakan untuk terus eksis di udara dan di dunia maya di era 4.0 ini. Hal itu dibuktikan dengan kehadiran TVMu, RadioMu, dan ratusan website Muhammadiyah yang dikelola pimpinan, AUM, kader dan anggota Muhammadiyah. Demikian juga dengan media cetak dan penerbitan terus berkembang menunjukkan kemajuan yang menggembirakan, meski harus terus memperoleh dukungan kuat dari seluruh warga dan amal usaha Pesyarikatan. Majalah Suara Muhammadiyah, Suara 'Aisyiyah, Majalah Tabligh, Majalah al Manar, dan beberapa media yang diterbitkan oleh PWM, PDM dan AUM (Tim Penulis, 2015). Seperti di PWM Sulawesi Selatan yang mengelola Majalah Khittah baik cetak maupun online secara online jadi semua orang bisa mengakses informasinya. Selain itu, dalam menghadapi era industri 4.0 Muhammadiyah juga tengah melakukan akselerasi dan ekspansi dengan tujuan untuk memajukan lembaga pendidikan Muhammadiyah mulai dari tingkat sekolah dasar hingga perguruan tinggi (Faruq, 2020).

Dalam era 4.0 saat ini, gerakan dakwah Muhammadiyah telah memberikan kemudahanan layanan dalam hal informasi, publikasi, dan komunikasi dengan menyempurnakan kualitas isi, meningkatkan kapasitas dan tampilan website dan pengembangan siaran radio streaming. Website yang memiliki 600 subdomain ini dipersiapkan untuk menampung website Majelis/Lembaga, Ortom, PWM, PDM dan AUM. Sebagai bentuk usaha memperluas dan meningkatkan layanan informasi kepada masyarakat, maka website tersebut disajikan dalam bahasa Indonesia, bahasa Arab, dan bahasa Inggris, sedang konten dan isi website tersebut memuat berita seputar dinamika 
organisasi, tuntunan beragama, putusan tarjih, amal usaha dan torjom. (Tim Penulis, 2015).

Visi pendidikan Muhammadiyah adalah terbangunnya kekuatan Muhammadiyah dalam pendidikan yang unggul, bersifat holistik dan bertatakelola baik di tingkat nasional dan regional. Oleh karenanya Muhammadiyah perlu secara terus menerus mendorong pengelolaan lembaga pendidikan yang inovatif dan berkualitas unggul. Dari 24 program yang telah disusun, terdapat 5 (lima) program prioritas sebagai fokus pembinaan yaitu meliputi; (1) Peningkatan Kualitas kepala Sekolah/Madrasah/Pondok Pesantren, (2) Pengembangan Sekolah/Madrasah/Pondok Pesantren sebagai Basis Kaderisasi, (3) Pengembangan Sekolah/Madrasah/Pondok Pesantren Unggulan dan Model, (4) Penguatan dan Pengembangan dan Penguatan Infrastruktur sekolah/madrasah/madrasah/Pondok Pesantren, dan (5) Olmpiade Ahmad Dahlan (Olimpicad) (Tim Penulis, 2015).

Lain hanya dengan PTM yang secara kuantitatif jumlahnya mengalami penurunan. Penurutnan itu dikarena adanya merger beberapa akademi, sekolah tinggi dan institut menjadi universitas. Namun, Penggabungan tersebut telah berdampak positif terhadap efisiensi, penguatan kelembagaan, dan daya saing PTM. Terdapat semangat yang tinggi di beberapa Pimpinan Daerah dan Wilayah untuk mendirikan PTM baru. Beberapa PTM membuka program studi, jurusan baru, dan jenjang pasca sarjana.

Lembaga pendidikan di lingkup organisasi Muhammadiyah wajib mengajarkan $\mathrm{Al}$ Islam dan Kemuhammadiyahan sesuai dengan pedoman pendidikan dasar dan menengah Muhammadiyah. Al Islam merupakan pelajaran yang berisikan Al-Quran dan Hadis, Aqidah Akhlak, dan Ibadah. Sedangkan Kemuhammadiyahan berfokus pada masalah pengkaderan dengan bekal kepemimpinan dan keorganisasian yang sesuai dengan akar pembentukan Muhammadiyah. Pada bidang pendidikan di era revolusi industri 4.0 proses pembelajarannya memanfaatkan kemajuan teknologi, penyelesaian tugas melalui berbagai informasi dari internet, hingga peningkatan kompetensi guru yang harus mampu menggunakan teknologi informasi (Saputra, Churrohman, \& Haryanto, 2019).

Memasuki abad kedua sejak berdirinya, Muhammadiyah berkomitmen kuat untuk melakukan gerakan pencerahan. Melalui gerakan tersebut, maka Muhammadiyah terus bergerak dalam mengemban misi dakwah dan tajdid untuk menghadirkan Islam sebagai ajaran yang mengembangkan sikap tengahan (Wasathiyah), membangun perdamaian, menghargai kemajemukan, menghormati harkat martabat kemanusiaan laki-laki maupun perempuan, mencerdaskan kehidupan bangsa, menjunjung tinggi akhlak mulia, dan memajukan kehidupan umat manusia (Tim Penulis, 2015d).

\section{SIMPULAN}

Berdasarkan uraian pada bagian sebelumnya, maka diperoleh kesimpulan bahwa kelahiran organisasi kemasyarakatan Muhammadiyah mengemban misi pencerahan dan pencerdasan dengan melakukan pembaharuan dalam bidang pendidikan Islam. Secara kuantitas jumlah amal usaha dalam bidang pendidikan di Muhammadiyah sangat banyak. Pemikiran pendidikan di Muhammadiyah dikenal dengan pendidikan Islam transformatif, karena tujuan pendidikan Muhammadiyah bukan hanya memberikan bekal yang dapat diaplikasikan dalam berbagai kondisi yang beraneka ragam, melainkan juga harus mampu mentransformasikan (mengubah) diri pribadi dan masyarakatnya. Dengan demikian pendidikan Muhammadiyah mendorong peserta didiknya untuk tidak hanya menguasai 
ilmu pengetahuan dan teknologi yang diajarkan, namun pada saat bersamaan bersedia menginternalisasi ilmu yang dipelajarinya ke dalam dirinya sehingga terjadi proses transformasi diri, dan bersedia berbagi dengan masyarakatnya. Bagi KH Ahmad Dahlan, pendidikan adalah alat untuk dakwah amar makruf nahi mungkar. Tujuan pendidikan tidak hanya berdimensi duniawi, tetapi mencakup dimensi ukhrawi.

Dalam pandangan Muhammadiyah Islam berkemajuan mengandung nilai-nilai kemajuan untuk membangun peradaban yang utama dan menjadi rahmat bagi semesta. Kemajuan tersebut adalah kebaikan yang serba utama, yang melahirkan keunggulan hidup lahiriah dan ruhaniah. Islam berkemajuan ingin mewujudkan kehidupan umat manusia yang tercerahkan melalui transformasi sosial yang bersifat emansipatoris, humanis, liberal, dan transenden.

Dari temuan di dalam pembahasan maka hasil artikel ini mengimplikasikan kepada seluruh warga persyarikatan Muhammadiyah untuk terus bersama masyarakat dalam memperbaiki negeri ini dari segala permasalahan yang dihadapi, khususnya dalam hal pendidikan Islam. Konsep Islam tengahan (Wasathiyah) diharapkan melahirkan perdamaian, menghargai kemajemukan, meghormati harkat martabat kemanusiaan lakilaki maupun perempuan, mencerdaskan kehidupan bangsa, menjunjung tinggi akhlak mulia, dan memajukan kehidupan umat manusia..

\section{UCAPAN TERIMA KASIH}

Artikel ini tersusun berkat pencerahan dari Prof. Dr. H. Syarifuddin Ondeng, M.Ag. dan Dr. Muh. Yahdi, M.Ag. Oleh karena itu, penulis mengucapkan terima kasih kepada kedua dosen tersebut sebagai pengampuh mata kuliah Sejarah Pendidikan Islam pada Program Pasca Sarjana Dirasah Islamiyah Konsentrasi Pendidikan dan Keguruan Universitas Islam Negeri Alauddin Makassar.

\section{DAFTAR PUSTAKA}

Ali, A. M. (1971). Alam pikiran modern di Indonesia. Jakarta: Jajasan Nida.

Ali, M. (2010). Reinvensi pendidikan Muhammadiyah. Jakarta Selatan: Al-Wasat Publishing House.

Arifin, Y. (2017). Pemikiran emas para tokoh pendidikan Islam. Yogyakarta: IRCiSoD.

Dahlan, Z. (2020). Respons Muhammadiyah di Indonesia terhadap ordonansi guru awal abad XX. Islamijah: Journal of Islamic Social Sciences, 1(1), 26-48. https://doi.org/10.30821/islamijah.v1i1.7173

Darsitun. (2020). Potret pendidikan Islam model Muhammadiyah dan perannya dalam pengembangan pendidikan Islam Indonesia. Tarbawi: Jurnal Pendidikan Agama Islam, 5(1).

Fadjar, A. M., Mulkhan, A. M., Maarif, A. S., Abdurrahman, A., Suny, I., Rais, M. A., Abdullah, M. A., Raharjo, M. D., Syamsuddin, M. D., Yusuf, M. Y., Soeratno, S. C., Sairin, S., Muhaimin, Y. A., \& Zamroni. (2005). Begawan Muhammadiyah bangsa rampai pidao pengukuhan guru besar tokoh Muhammadiyah. Jakarta: Pusat Studi Agama dan Peradaban (PSAP) Muhammadiyah.

Faruq, U. Al. (2020). Peluang dan tantangan pendidikan Muhammadiyah Di Era 4.0. ArRisalah: Media Keislaman, Pendidikan Dan Hukum Islam, 18(1), 13-30. 
Ismail, L., \& Risfaisal. (2017). Eksistensi gerakan muhammadiyah dalam pendidikan di era modernisasi (Studi Kasus MI Muhammadiyah Pallatabbua, MTs Muhammadiyah Mandalle, MA Muhammadiyah Limbung). Jurnal Equilibrium Pendidikan Sosiologi, $5(1)$.

Kholili, A. N., \& Fajaruddin, S. (2020). Manajemen strategik peningkatan mutu lembaga pendidikan muhammadiyah di Kabupaten Gunungkidul. Jurnal Akuntabilitas Manajemen Pendidikan, 8(1), 53-69. https://doi.org/10.21831/jamp.v8i1.31630

Lenggono, W. (2018). Lembaga pendidikan muhammadiyah (telaah pemikiran K.H. Ahmad Dahlan tentang pembaruan pendidikan Islam di Indonesia). Islãmadîna: Jurnal Pemikiran Islam, 19(1).

Luthfi, F., \& Latif, W. (2020). Sinergitas Nahdlatul Ulama dan Muhammadiyah dalam pengembangan ekonomi Islam di Indonesia. Al-Urban: Jurnal Ekonomi Syariah Dan Filantropi Islam, 5(1), 1-12. https://doi.org/10.22236/alurban_vol3/is2pp137148

Mas, S. (2005). Muhammadiyah pintu gerbang protestanisme Islam sebuah presisi modernitas. Mojokerto: Al Hikmah.

Mubaroq, A. I., Maulana, A., \& Basri, H. (2020). Konsep pendidikan Islam dalam perspektif Kiai Haji Ahmad Dahlan. TAMADDUN, 2(2), 92-102. https://doi.org/10.30587/tamaddun.v20i2.1305

Novriadi, D., \& Syubli. (2021). Analisis perbandingan pemikiran KH Ahmad Dahlan dan KH. Hasyim Asy'ari tentang pendidikan Islam di Indonesia. El-Ta'dib (Journal of Islamic Education), 1(1). http://jurnal.umb.ac.id/index.php/eltadib/article/view/1446

Printina, B. I. (2019). Membumikan moral dan cita benih bangsa. Yogyakarta: Deepublish.

Ridlo, S. (2020). Pembaharuan pendidikan Islam di Indonesia. Syaikhuna: Jurnal Pendidikan dan Pranata Islam, 11(1), 79-104. https://doi.org/10.36835/syaikhuna.v11i1.3846

Ruslan, A. (2020). Falsafah ajaran kyai Ahmad Dahlan dan etos pendidikan Muhammadiyah. CHRONOLOGIA, 2(1), 46-54.

Saihu, S. (2020). Konsep pembaharuan pendidikan Islam menurut Fazlurrahman. Andragogi: Jurnal Pendidikan Islam Dan Manajemen Pendidikan Islam, 2(1), 83-99. https://doi.org/10.36671/andragogi.v2i1.76

Salam, J. (2009). K.H. Ahmad Dahlan amal dan perjuangannya. Banten: Al Wasat.

Saputra, B. A., Churrohman, T., \& Haryanto, B. (2019). Optimalisasi pembelajaran al Islam dan kemuhammadiyahan terintegrasi literasi digital guna menghadapi tantangan era 4.0. Tajdida: Jurnal Pemikiran Dan Gerakan Muhammadiyah, 17(1).

Sukandar, A. A., \& Hori, M. (2020). Pemikiran pendidikan Islam: sumbangan para tokoh pendidikan Islam melalui gagasan, teori, dan aplikasi. CV Cendekia Press.

Syafruddin, D., Wahid, D., Darmadi, D., Umam, S., Ropi, I., Hendarmin, L., Nisa, Y. F., Thaha, I., Saputra, R. E., Garadian, E. A., Maulana, D., Mudzakir, I. I., Rohayati, T., \& Abdallah. (2018). Potret guru agama: pandangan tentang toleransi dan isu-isu kehidupan keagamaan. Jakarta: Kencana.

Syaifuddin, M. A., Anggraeni, H., Khotimah, P. C., \& Mahfud, C. (2019). Sejarah sosial pendidikan Islam modern di Muhammadiyah. Tadarus: Jurnal Pendidikan Islam, $8(1)$. 
Syam, N., \& Nawawi. (2019). Islam Nusantara berkemajuan sebagai basis modernisasi Islam di Indonesia. ISLAMICA: Jurnal Studi Keislaman, 13(2).

Tim Penulis. (2015a). Indonesia berkemajuan rekonstruksi kehidupan kebangsaan yang bermakna. Yogyakarta: Pimpinan Pusat Muhammadiyah.

Tim Penulis. (2015b). Laporan muktamar Muhammadiyah ke-47 Tahun 2015. Yogyakarta: Pimpinan Pusat Muhammadiyah.

Tim Penulis. (2015c). Negara pancasila sebagai Darul Ahdi Wa Syahadah. Yogyakarta: Pimpinan Pusat Muhammadiyah.

Tim Penulis. (2015d). Pernyataan pikiran Muhammadiyah abad kedua. Yogyakarta: Percetakan Muhammadiyah Gramasurya.

Tim Penulis. (2020a). Muhammadiyah. https://id.wikipedia.org/wiki/Muhammadiyah

Tim Penulis. (2020b). Sejarah Muhammadiyah. https://muhammadiyah.or.id/sejarahmuhammadiyah/

Tim Penulis. (2020c). Sejarah singkat Muhammadiyah. https://muhammadiyah.or.id/sejarah-singkat-muhammadiyah/

Widiyastuti. (n.d.). Memori keluarga KH Ahmad Dahlan. http://mpi.muhammadiyah.or.id

Widodo, H. (2019). Pendidikan holistik berbasis budaya sekolah. Yogyakarta: UAD Press.

Yusra, N. (2018). Muhammadiyah: gerakan pembaharuan pendidikan Islam. POTENSIA: Jurnal Kependidikan Islam, 4(1). 